\title{
Tetracycline Resistance Determinants from Groups A to D Vary in Their Ability to Confer Decreased Accumulation of Tetracycline Derivatives by Escherichia coli
}

\author{
By IAN CHOPRA, * STUART SHALES AND PETER BALL \\ Department of Microbiology, University of Bristol, Bristol BS8 1 TD, U.K.
}

(Received 29 September 1981)

\begin{abstract}
The ability of four genetically distinct plasmid-located tetracycline resistance determinants (TetA, B, C and D) to confer decreased accumulation of tetracycline and some of its analogues by Escherichia coli $\mathrm{K} 12$ was examined. Accumulation of oxytetracycline, tetracycline, demethylchlorotetracycline, 6-demethyl-6-deoxy-5-hydroxy-6-methylenetetracycline, chlorotetracycline, doxycycline and 6-demethyl-6-deoxytetracycline was examined by fluorescence spectroscopy. The determinants varied in their ability to promote decreased accumulation of tetracyclines, defined as an $\mathrm{R}^{+} / \mathrm{R}^{-}$fluorescence ratio of $<0.85$. Plasmid pIP7 (TetA) caused reduced accumulation of only oxytetracycline, tetracycline and chlorotetracycline, but plasmid pDU301 (TetB) promoted reduced accumulation of all the compounds tested except 6-demethyl-6-deoxytetracycline. The TetC determinant of pBR322 caused decreased uptake of five derivatives, but not doxycycline or 6-demethyl-6-deoxytetracycline. Plasmid RA1 (TetD) encoded reduced accumulation of oxytetracycline, tetracycline, 6-demethyl-6-deoxy-5-hydroxy-6-methylenetetracycline and chlorotetracycline. In general, the resistance determinants were more efficient in promoting decreased accumulation of hydrophilic tetracyclines. These accumulation studies provide a satisfactory method for the phenotypic identification of Tet resistance determinants.
\end{abstract}

\section{INTRODUCTION}

In many bacterial species the genes that specify resistance to tetracycline are plasmid-located (for a recent review, see Chopra et al., 1981a). The use of DNA-DNA hybridization techniques on plasmids found in Gram-negative bacteria has revealed the presence of at least four classes (TetA to TetD) of tetracycline resistance determinants (Mendez et al., 1980). However, each determinant specifies a resistance mechanism which involves decreased accumulation of tetracycline (Ball et al., 1980; McMurry et al., 1980; Shales et al., 1980). The lack of nucleotide sequence homology between the resistance determinants implies that the products conferring decreased tetracycline accumulation are not identical. In view of this, it seems plausible that the resistance determinants may code for products which promote decreased accumulation of tetracycline, but which vary in their ability to confer decreased accumulation of other tetracyclines. We have now examined this question.

\section{METHODS}

Bacterial strains and plasmids. The plasmid-free host strain used throughout this work was Escherichia coli K12 strain JC3272 (Achtman et al., 1971). Plasmids pIP7 (TetA) (Shales et al., 1980; Mendez et al., 1980), pDU301 (TetB) (Shales et al., 1980) and RA1 (TetD) (Mendez et al., 1980) were introduced into JC3272 by conjugation. Plasmid pBR322 (derived from TetC) (Sutcliffe, 1978; Mendez et al., 1980) was obtained from Dr P. M. Bennett and introduced into JC 3272 by transformation. 
Tetracyclines. Tetracycline, oxytetracycline and chlorotetracycline were purchased from Sigma. Demethylchlorotetracycline, 6-demethyl-6-deoxy-5-hydroxy-6-methylenetetracycline, 6-demethyl-6-deoxytetracycline and minocycline were gifts from Lederle Laboratories. Doxycycline was kindly donated by Pfizer Ltd.

General methods. Concentrations of antibiotic causing a $50 \%$ reduction in growth rate $\left(\mathrm{IC}_{50}\right)$ were determined as described by Shales et al. (1980). Resistance was induced by growth of cultures in the presence of tetracycline $\left(0.5 \mu \mathrm{g} \mathrm{ml}^{-1}\right)$. Accumulation of tetracyclines was assayed by spectrofluorimetry (Samra et al., 1978; Ball et al., 1980; Shales et al., 1980).

\section{RESULTS}

Phenotypic patterns of resistance mediated by determinants of groups $A$ to $D$

Mendez et al. (1980) reported that TetB determinants encode resistance to both tetracycline and minocycline. Previous studies in this laboratory (Shales et al., 1980; Chopra et al., 1981 b) have confirmed these observations, but in contrast to the data of Mendez et al. (1980) we have found that RA1 (TetD) encodes minocycline resistance (Table 1). Since pSC101 only confers resistance to tetracycline (Shales et al., 1980; Mendez et al., 1980) a similar phenotype might also be expected for pBR322, which is a derivative of pSC101 (Sutcliffe, 1978). However, pBR322 does mediate resistance to minocycline (Table 1).

\section{Ability of determinants to confer decreased accumulation of tetracycline and some of its analogues}

Various tetracyclines can be used as fluorescent probes of their own accumulation by bacteria (Samra et al., 1978; Ball et al., 1980; Shales et al., 1980). Using a spectrofluorimetric method, the ability of determinants from groups $A$ to $D$ to confer decreased accumulation of tetracycline and some of its analogues was examined. Decreased accumulation was considered to occur when the $R^{+} / R^{-}$fluorescence ratio was $<0 \cdot 85$. On this basis the determinants varied in their ability to promote decreased accumulation of tetracyclines (Table 2). Plasmid pIP7 (TetA) only caused reduced accumulation of oxytetracycline, tetracycline and chlorotetracycline. Plasmid pDU301 (TetB) promoted reduced accumulation of oxytetracycline, tetracycline, demethylchlorotetracycline, 6demethyl-6-deoxy-5-hydroxy-6-methylenetetracycline, chlorotetracycline and doxycycline. Plasmid pBR322 (TetC) caused reduced accumulation of oxytetracycline, tetracycline, demethylchlorotetracycline, 6-demethyl-6-deoxy-5-hydroxy-6-methylenetetracycline and chlorotetracycline. Plasmid RA1 (TetD) encoded reduced accumulation of oxytetracycline, tetracycline, 6-demethyl-6-deoxy-5-hydroxy-6-methylenetetracycline and chlorotetracycline.

In general, the resistance determinants were more efficient in promoting decreased accumulation of hydrophilic tetracyclines (Table 2). For example, most determinants caused reduced accumulation of analogues with partition coefficients $\leqslant 0.32$ (hydrophilic compounds), but none encoded reduced uptake of 6-demethyl-6-deoxytetracycline and only one (pDU301, TetB) conferred decreased accumulation of doxycycline. Both these antibiotics are hydrophobic (partition coefficients $>0 \cdot 32$ ) (Table 2 ).

\section{DIS CUSSION}

In a previous paper (Shales et al., 1980) we reported our inability to detect decreased tetracycline accumulation in cells harbouring pSC101. In contrast, cells containing pBR322 exhibit decreased drug accumulation (Table 2). Although pBR322 contains only part of the tetracycline resistance region of pSC101, the copy number of pBR322 (20-30 copies per chromosome; Boyer et al., 1977) is greater than that of $\mathrm{pSC} 101$ (6-8 copies per chromosome; Bukhari et al., 1977). These findings imply that the fluorescence assay might measure reduced drug accumulation only when the quantity of plasmid products reaches a certain level within the cell. 
Table 1. Resistance profiles to tetracycline and minocycline of uninduced and induced cultures of E. coli K12 JC3272 containing different plasmids

\begin{tabular}{|c|c|c|c|c|c|}
\hline \multirow[b]{2}{*}{ Plasmid } & \multirow{2}{*}{$\begin{array}{l}\text { Phenotypic } \\
\text { classification } \\
\text { of resistance } \\
\text { determinant } \dagger\end{array}$} & \multicolumn{2}{|c|}{$\begin{array}{l}\text { Resistance level }\left(\mathrm{IC}_{50}\right) \text { to } \\
\text { tetracycline }\left(\mu \mathrm{g} \mathrm{ml}^{-1}\right) \ddagger\end{array}$} & \multicolumn{2}{|c|}{$\begin{array}{l}\text { Resistance level }\left(\mathrm{IC}_{50}\right) \text { to } \\
\text { minocycline }\left(\mu \mathrm{g} \mathrm{m}^{-1}\right) \ddagger\end{array}$} \\
\hline & & Uninduced & Induced & Uninduced & Induced \\
\hline None & None & $0.29 \pm 0.02$ & ND & $0.42 \pm 0.08$ & ND \\
\hline pIP7 & TetA & $3.1 \pm 0.1$ & $21 \cdot 0 \pm 2 \cdot 0$ & $0.37 \pm 0.04$ & $0.45 \pm 0.01$ \\
\hline pDU301* & TetB & $61 \cdot 0 \pm 1 \cdot 0$ & $\overrightarrow{\mathrm{ND}}$ & $2.35 \pm 0.25$ & ND \\
\hline pBR322* & Derived from TetC & $32 \cdot 0 \pm 5 \cdot 5$ & ND & $1.20 \pm 0.30$ & ND \\
\hline RA1 & TetD & $15 \cdot 3 \pm 1 \cdot 1$ & $47 \cdot 3 \pm 6 \cdot 3$ & $1 \cdot 1 \pm 0$ & $2.7 \pm 0.2$ \\
\hline
\end{tabular}

ND, Not determined.

* Expression of resistance by these plasmids is constitutive.

$\uparrow$ According to the scheme of Mendez et al. (1980). The tetracycline resistance determinant of pBR322 is derived from that in pSC 101 (Sutcliffe, 1978); the latter contains a TetC determinant (Mendez et al., 1980).

$\ddagger$ Mean values \pm 1 standard deviation.

Table 2. Partition coefficients and antibiotic accumulation in strains of E. coli containing different plasmids

\begin{tabular}{|c|c|c|c|c|c|c|}
\hline \multirow[b]{2}{*}{ Antibiotic } & \multirow{2}{*}{$\begin{array}{c}\text { Partition } \\
\text { coefficient } \\
\text { (octanol/aqueous } \\
\text { buffer) } \\
\text { at pH } 6 \cdot 6^{*}\end{array}$} & \multirow{2}{*}{$\begin{array}{c}\text { Antibiotic } \\
\text { accumulation } \\
\text { (arbitrary } \\
\text { fluorescence } \\
\text { units) in } \\
\mathbf{R}^{-} \text {host } \dagger\end{array}$} & \multicolumn{4}{|c|}{$\begin{array}{l}\text { Ratio of antibiotic accumulation }\left(\mathbf{R}^{+} / \mathbf{R}^{-}\right) \\
\text {in strains containing different plasmids }\end{array}$} \\
\hline & & & $\begin{array}{c}\text { pIP7 } \\
\text { (TetA) }\end{array}$ & $\begin{array}{l}\text { pDU301 } \\
\text { (TetB) }\end{array}$ & $\begin{array}{c}\text { pBR322 } \\
\text { (TetC) }\end{array}$ & $\begin{array}{l}\text { RA1 } \\
(\text { TetD) }\end{array}$ \\
\hline Oxytetracycline & 0.087 & $45 \cdot 8$ & 0.11 & 0.19 & 0.43 & 0.26 \\
\hline Tetracycline & 0.052 & $79 \cdot 2$ & 0.08 & 0.13 & 0.31 & 0.15 \\
\hline Demethylchlorotetracycline & 0.19 & $58 \cdot 3$ & 1.62 & 0.31 & 0.53 & $1 \cdot 39$ \\
\hline 6-Demethyl-6-deoxy-5-hydroxy- & & & & & & \\
\hline 6-methylenetetracycline & NR & $65 \cdot 0$ & 0.95 & 0.25 & 0.29 & 0.47 \\
\hline Chlorotetracycline & 0.32 & $73 \cdot 8$ & 0.67 & 0.13 & 0.31 & 0.60 \\
\hline Doxycycline & 0.92 & $122 \cdot 0$ & $1 \cdot 22$ & 0.58 & 1.08 & 0.86 \\
\hline 6-Demethyl-6-deoxytetracycline & 0.96 & $85 \cdot 0$ & 0.92 & 0.85 & 0.87 & 1.04 \\
\hline
\end{tabular}

Despite limitations on the use of fluorescence spectroscopy to examine tetracycline accumulation in cells containing $\mathrm{pSC} 101$, the method is generally versatile and permits studies on the accumulation of tetracycline derivatives which are not readily available in a radioactive form (Samra et al., 1978). Data presented here show that different classes of tetracycline resistance determinants vary in their ability to promote decreased accumulation of tetracycline derivatives. Thus, the lack of nucleotide sequence homology between these determinants (Mendez et al., 1980) could be due at least partially to differences in the products mediating decreased drug accumulation. Reduced tetracycline accumulation mediated by $\operatorname{Tn} 10$ (TetB) results from insertion of a 36 kilodalton protein into the cytoplasmic membrane of $E$. coli (Levy et al., 1977; Chopra et al., 1981 c) and proteins of similar molecular weights have been implicated in reduced accumulation of tetracycline mediated by pBR322 (see Chopra et al., 1981a) and pRSD1 (TetA) (R. Schmitt, personal communication). However, attempts to compare these proteins on the basis of mass alone could be misleading because requirements for membrane insertion may necessitate that the various resistance proteins have similar sizes. Isoelectric point determinations on the membrane proteins could answer the question of whether they differ, but to date only the Tn10 (TetB) product has been examined (pI 6.4) (Chopra et al., 1981 c). 
The ability of the resistance determinants to promote decreased accumulation of hydrophobic derivatives such as doxycycline and 6-demethyl-6-deoxytetracycline is poor (Table 2). Accumulation of minocycline (partition coefficient 1.48 at $\mathrm{pH} \mathrm{6.6)} \mathrm{was} \mathrm{not}$ investigated, but it is presumed to behave in a similar fashion to 6-demethyl-6-deoxytetracycline. Indeed, $E$. coli carrying a TetB determinant accumulates equivalent amounts of minocycline to the plasmid-free host (Shales et al., 1980). Plasmid-determined resistance to such hydrophobic tetracyclines probably involves ribosomal alterations (Shales et al., 1980).

Mendez et al. (1980) reported that the levels of resistance to tetracycline, minocycline and $\beta$-chelocardin conferred by determinants $A$ to $D$ could be useful in distinguishing between them. Apart from the case of TetA determinants, we have found resistance levels to be a less useful criterion for phenotypic identification of the three classes B to D (Table 1). In contrast, the accumulation studies reported here clearly distinguish the four categories of resistance determinant.

This work was supported by project grants from the Medical Research Council to I.C.

\section{REFERENCES}

Achtman, M., Willetts, N. \& Clark, A. J. (1971). Beginning a genetic analysis of conjugational transfer determined by the F factor in Escherichia coli by isolation and characterization of transfer-deficient mutants. Journal of Bacteriology 106, 529-538.

Ball, P. R., Shales, S. W. \& Chopra, I. (1980). Plasmid-mediated tetracycline resistance in Escherichia coli involves increased efflux of the antibiotic. Biochemical and Biophysical Research Communications 93, 74-81.

Boyer, H. W., Betlach, M., Bolivar, F., Rodriguez, R. L., Heyneker, H. L., Shine, J. \& GoodmaN, H. M. (1977). The construction of molecular cloning vehicles. In Recombinant Molecules: Impact on Science and Society, pp. 9-20. Edited by R. F. Beers \& E. G. Bassett. New York: Raven Press.

Bukhari, A. I., Shapiro, J. L. \& Adhya, S. L. (editors) (1977). DNA Insertion Elements, Plasmids and Episomes. Cold Spring Harbor, New York: Cold Spring Harbor Laboratory.

Chopra, I., Howe, T. G. B., Linton, A. H., Linton, K. B., Richmond, M. H. \& Speller, D. C. E. $(1981 a)$. The tetracyclines: prospects at the beginning of the 1980s. Journal of Antimicrobial Chemotherapy 8, 5-21.

Chopra, I., Shales, S. W., Ward, J. M. \& Wallace, L. J. (1981b). Reduced expression of Tn10-mediated tetracycline resistance in Escherichia coli containing more than one copy of the transposon. Journal of General Microbiology 126, 45-54.

Chopra, I., Ball, P. R., Eccles, S. J. \& Shales, S. W. $(1981 c)$. Nature and function of Tn10-encoded proteins that mediate tetracycline resistance in Escherichia coli. In Molecular Biology, Patho- genicity, and Ecology of Bacterial Plasmids, p. 592. Edited by S. B. Levy. New York: Plenum Publishing Corp.

Colaizzi, J. L. \& KLINK, P. R. (1969). pH-partition behaviour of tetracyclines. Journal of Pharmaceutical Sciences 58, 1184-1189.

Levy, S. B., McMurRy, L., Onigman, P. \& SAunders, R. M. (1977). Plasmid-mediated tetracycline resistance in Escherichia coli. In Topics in Infectious Diseases, vol. 2, pp. 181-203. Edited by J. Drews \& G. Hogenauer. New York: Springer Verlag.

McMurry, L., Petrucci, R. E. \& Levy, S. B. (1980). Active efflux of tetracycline encoded by four genetically different tetracycline resistance determinants in Escherichia coli. Proceedings of the National Academy of Sciences of the United States of America 77, 3974-3977.

Mendez, B., Tachibana, C. \& Levy, S. B. (1980). Heterogeneity of tetracycline resistance determinants. Plasmid 3, 99-108.

SAmRA, Z., KRAuszsteinmetz, J. \& Sompolinsky, D. (1978). Transport of tetracyclines through the bacterial cell membrane assayed by fluorescencestudy with susceptible and resistant strains of Staphylococcus aureus and Escherichia coli. Microbios 21, 7-12.

Shales, S. W., Chopra, I. \& Ball, P. R. (1980). Evidence for more than one mechanism of plasmiddetermined tetracycline resistance in Escherichia coli. Journal of General Microbiology 121, 221-229.

SuTCLIFFE, J. G. (1978). Complete nucleotide sequence of the Escherichia coli plasmid pBR322. Cold Spring Harbor Symposia on Quantitative Biology 43, 77-90. 